\section{Educación Artística y comunicación del Patrimonio de Al-Ándalus a través del diseño textil contemporáneo. Una propuesta didáctica y pictórica para el ámbito educativo}

María Dolores Gallego Martínez ${ }^{(1)}$

\begin{abstract}
Resumen: Este artículo se presenta como una propuesta didáctica y creativa de innovación docente y que se enmarca en el Programa Educativo y Cultural denominado 'Vivir y Sentir el Patrimonio' de la Consejería de Educación y Deporte de la Junta de Andalucía. Partiendo de la experiencia y conocimiento de la propia autora -como artista visual, investigadora y docente universitaria- se ofrece un proyecto en torno a la Educación Artística y Patrimonial de un marcado carácter innovador y con foco en el Conjunto Monumental de la Alhambra y el Generalife de Granada (España). Así pues, a través de la investigación, el diseño y la creación artística, se profundizará en el conocimiento y la interpretación del arte geométrico tan característico de los alicatados cerámicos de Al-Ándalus para su posterior aplicación al diseño textil contemporáneo -e incluso al diseño de prendas de vestirempleando una serie de técnicas manuales y artesanales como la estampación en bloque o el dibujo con hilos. De este modo, desde el contexto educativo y aplicando la metodología aprendiendo haciendo o learning by doing, el alumnado desarrollará su creatividad creando un diseño textil propio y único, pero también comprenderá el significado y el valor de este bien patrimonial de Al-Ándalus, promoviendo así su propia conciencia patrimonial individual y colectiva, como la conservación y difusión del patrimonio andaluz.
\end{abstract}

Palabras clave: Educación Artística - Educación Patrimonial - Metodología Learning by doing - diseño textil - alicatado andalusí.

[Resúmenes en inglés y portugués en las páginas 158-159]

(1) María Dolores Gallego Martínez es artista visual, investigadora y docente del Área de Didáctica de la Expresión Plástica de la Facultad de Ciencias de la Educación de la Universidad de Almería - UAL (España). Doctora en Historia y Artes.. Licenciada en Bellas Artes, Máster en Producción e Investigación y Arte y Máster en Dibujo: Ilustración, Cómic y Creación Audiovisual por la Universidad de Granada. Sus obras han sido exhibidas en museos, centros de arte, bienales y ferias de arte de España, Portugal, Italia, Grecia, Jordania y Estados Unidos; siendo galardonada con diversos premios. Cuenta con publicaciones, artículos científicos y capítulos de libros. 


\section{Introducción}

La Educación artística ofrece a las personas desarrollar una sensibilidad, percepción e interpretación diferente del mundo en el que vivimos. Para ello, las prácticas artísticas contemporáneas son una metodología válida y útil para trabajar transversalmente diversos contenidos de múltiples materias en el aula.

Se observa, como una necesidad patente, el dar a conocer al alumnado de los diversos niveles educativos (formales y no formales) los variados modos de hacer o formas de laborar de los artistas contemporáneos ya que, de este modo, los creadores actuales nos hablan, cuestionan e interpretan diversas cuestiones de nuestra sociedad e historia a través de diversos lenguajes y medios artísticos. Por medio de sus obras de arte actuales, los individuos pueden analizar críticamente y ser conscientes de los diversos aspectos históricos, culturales y sociales que nos influyen y moldean.

"Autores como Llull (2005) y Tapia (2011) hablan del Patrimonio de una ciudad como todos aquellos bienes heredados del pasado que tienen un valor cultural e histórico y conforman la memoria e identidad de dicha ciudad" (Rubio, 2020, p. 4), pero también modelan la memoria e identidad de las personas que habitan en ella.

En nuestra sociedad digital y cultura contemporánea, la imagen, lo visual y las TIC tienen un papel importantísimo en nuestra formación y conocimiento sobre el mundo (Muñoz Rey, 2021, p. 47). Las imágenes permiten interrelaciones y desarrollar aprendizajes significativos ya que dan lugar a varias lecturas, transmiten valores, pensamientos, ideas, sentimientos, etc. A través de las imágenes, y sin palabras, podemos representar cómo percibimos y vivimos el mundo. Las imágenes ofrecen muchas posibilidades didácticas y, por ello, es necesario reflexionar sobre ellas, sus usos, cómo se construyen y para qué se emplean. De ahí, nuestra presente propuesta con foco en educar con las imágenes y a través de ellas; educar y aprender a través de las prácticas artísticas contemporáneas y la experimentación plástica; y de entender el arte como un modo de producción de conocimiento (Siegmun, 2011).

En este marco que acabamos de exponer, planteamos un artículo en torno a una propuesta didáctica y creativa de innovación docente que se enmarca en el Programa Educativo y Cultural denominado 'Vivir y Sentir el Patrimonio' de la Consejería de Educación y Deporte de la Junta de Andalucía (España).

Partiendo de la experiencia y conocimiento de la propia autora -como artista visual, investigadora y docente universitaria- se ofrece un proyecto listo para ser puesto en práctica en el aula en torno a la Educación Artística y Patrimonial y con foco en el Conjunto Monumental de la Alhambra y el Generalife de Granada (España). Así pues, a través de un proceso de investigación visual, de diseño contemporáneo y de creación artística, se profundizará en el conocimiento y la interpretación de los alicatados cerámicos de Al-Ándalus, tan característicos del sur de España y el norte de Marruecos, y como Patrimonio Cultural y Artístico mundial. 


\section{El Patrimonio de Al-Ándalus: la Alhambra como inspiración}

En Andalucía (España), y por extensión en la Península Ibérica, el periodo de Al-Ándalus, comprendido entre el año 711 y 1492, tiene hasta nuestros días una gran importancia y presencia en la identidad, la cultura y la sociedad de este territorio del sur de Europa. Durante estos siete siglos de la historia, nuestro territorio vivió un desarrollo y esplendor cultural sin precedentes hasta entonces, llegando a convertirse en la expresión del grado de civilización más alto de la cultura medieval y dejando una huella muy marcada en la arquitectura o la cerámica andalusí, por ejemplo, hasta nuestros días.

Entre todos los monumentos que hemos heredado y conservado de este periodo, y que se pueden visitar en la actualidad, podemos destacar la Mezquita de Córdoba, el Real Alcázar de Sevilla o el Complejo Monumental de la Alhambra de Granada; todos ellos localizados en las capitales de las provincias andaluzas mencionadas.

En referencia a la Alhambra, es de subrayar que su valor artístico y patrimonial fue reconocido oficialmente y por primera vez en 1870, cuando fue declarada Monumento Nacional, Histórico y Artístico (Orden de la Regencia del reino de 10 de febrero de 1870, confirmada por la Real Orden de 21 de Julio de 1872 y ampliada por la Real Orden de 11 de junio de 1876). Con posterioridad, en 1943, se declararon Jardines Históricos a los jardines de la Alhambra y el Generalife y, "en la Convención de la UNESCO celebrada en Buenos Aires (Argentina), entre el 29 de octubre y el 2 de noviembre de 1984, el Comité del Patrimonio Mundial procedió a inscribir oficialmente en la Lista de dicho Patrimonio a la Alhambra y el Generalife de Granada" (Patronato de la Alhambra, s.f.a).

Así, pues, podemos destacar que la ciudad palatina de la Alhambra de Granada -que en la actualidad está configurada por edificios de diferentes estilos y momentos históricos- se caracteriza por la singularidad y belleza de la arquitectura y los motivos decorativos andalusíes del interior de las estancias y los patios de sus palacios ya que "representan la síntesis del arte, la arquitectura y la artesanía del último reino islámico en la Península Ibérica: el Reino Nazarí” (Gallego Martínez, 2013, p. 43). Unos palacios y decoraciones que asombran a cualquier visitante, sea cual sea su lugar de procedencia u origen.

Las paredes, cubiertas de yeserías (en la parte superior y/o en el techo y en su origen policromadas) y alicatados (presentes en la parte inferior o zócalos), son un laberinto de motivos geométricos, caligráficos y vegetales en relieve que se repiten múltiples veces y reflejan en el agua de sus estanques y fuentes hasta el infinito. Una obra monumental que, en su globalidad y como hemos indicado con anterioridad, hibrida arte, diseño y artesanía ya que, en el islam, "no hay artes independientes. Pintura, Caligrafía, Relieve y arquitectura se desarrollan unitariamente para conformar el hábitat. Los conceptos de utilidad y belleza van indeleblemente unidos" (Cabrera, 1994, p. 79).

En suma, la Alhambra de Granada, ya desde los viajeros románticos, ha sido una fuente de inspiración para creadores nacionales e internacionales de diversas disciplinas artísticas como el escritor estadounidense Washington Irving (1783-1859); los británicos Richard Ford (1796-1858) -hispanista- y Owen Jones (1809-1874) -arquitecto y artista orientalista-; el artista neerlandés M. C. Escher (1898-1972), entre otros; llegando así a ocupar, durante el siglo XIX, un importante lugar en el imaginario cultural europeo. 
La ciudadela en sí misma, se convirtió en la avanzadilla continental de un mundo oriental cargado de leyendas, riqueza y exotismos (...). Los viajeros del siglo XVIII vinculados al Grand Tour, (...) van a propagar una serie de imágenes e interpretaciones que van a tener su continuidad en el siglo XIX con la llegada de personajes ilustres -escritores y pintores, sobre todo- (...).

La interpretación romántica de la Alhambra desde el "orientalismo" va a convertir a este conjunto monumental en un modelo a partir del cual la arquitectura y la pintura historicista recrearán modelos por todo el mundo dando lugar a la corriente "alhambrista" que tanto éxito tuvo en exposiciones universales y en el continente americano (Patronato de la Alhambra, s.f.b).

En la actualidad, la cultura y arte de este periodo y complejo monumental, sigue siendo un imparable estro para multitud de artistas contemporáneos como Sean Scully (Dublín, Irlanda, 1945), Younès Rahmoun (Tetuán, Marruecos, 1975), Soledad Sevilla (Valencia, España, 1944) o Ángeles Agrela (Úbeda - Jaén, España, 1966), por ejemplo. En esta línea de investigación y creación artística contemporánea, podemos destacar el proyecto Textiles Alhambrescos de autoría propia. Un proyecto híbrido de pintura y diseño textil que vamos a detenernos a explicar en el siguiente apartado.

\section{Textiles Alhambrescos: un proyecto de pintura y diseño textil contemporáneo}

Como resultado del trabajo de investigación y creación artística desarrollado in situ entre 2013 y 2015, el proyecto artístico Textiles Alhambrescos fusiona tradición y contemporaneidad desde la óptica de una artista de Andalucía como es María Dolores Gallego (Torreperogil, Jaén, 1988).

Inspirado en la geometría de los alicatados o zelliges que decoran las partes inferiores de las paredes o muros del interior de los Palacios Nazaríes de la Alhambra de Granada, el proyecto se compone de una serie de formatos de diversas dimensiones y a modo de colección de pintura y de diseños textiles contemporáneos en los que se han combinado técnicas manuales tradicionales e innovadoras del estampado y el diseño de tejidos.

Así, las teselas geométricas y de terracota esmaltada de colores que componen -rellenando toda la superficie del plano sin dejar vacíos- los alicatados o mosaicos geométricos ornamentales, decorativos y funcionales de la Alhambra (Figuras 1 y 2), tan característicos del norte de Marruecos y el sur de España, se convierten en elementos aislados y motivos compositivos en los nuevos diseños textiles y pinturas creadas.

También, cabe mencionar que, aunque los alicatados o mosaicos geométricos muestran una visión general de unidad y perfección en las formas, estos están formados por teselas cerámicas realizadas manual y artesanalmente. Por tanto, cada pieza cerámica conserva su historia, identidad y personalidad única dentro de unas repetidas formas geométricas de cierta irregularidad. 

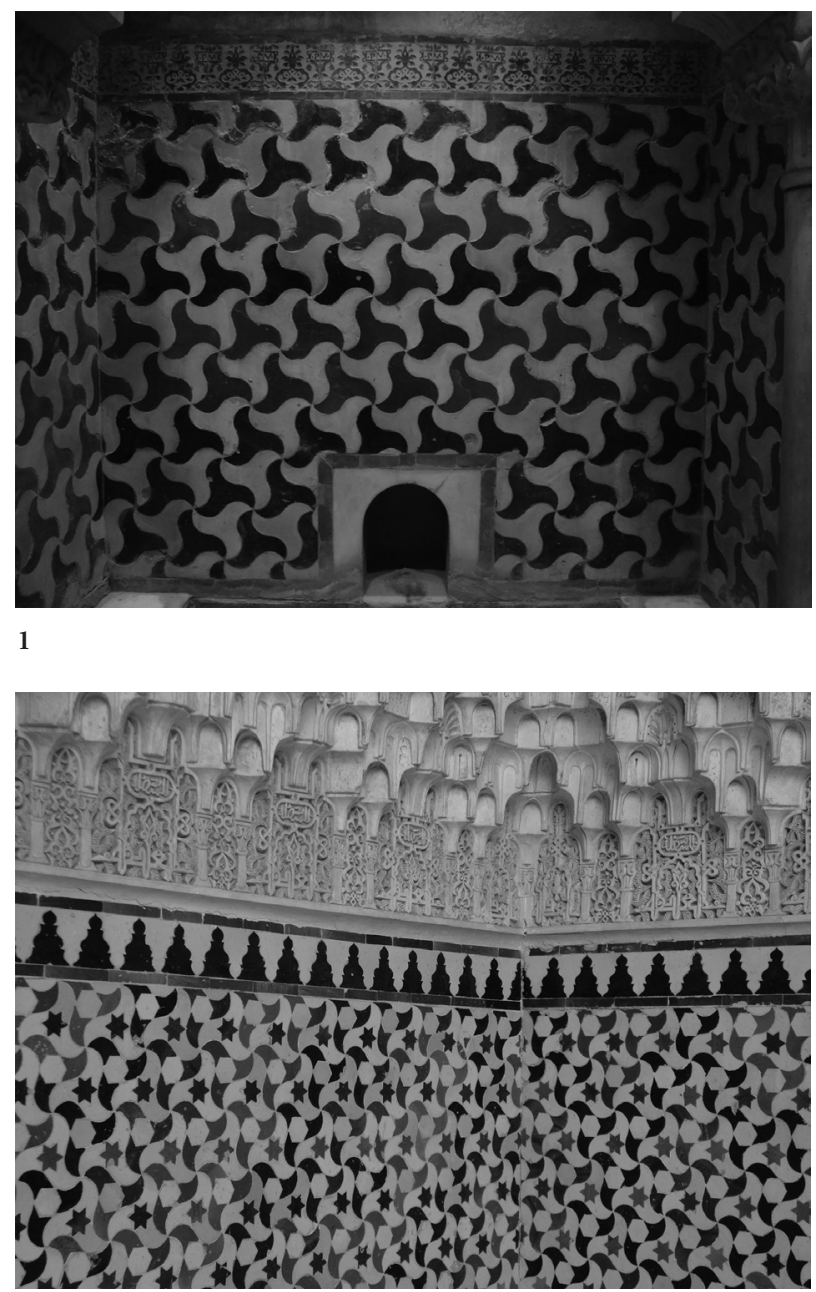

2
Figuras 1 y 2.

Fotografías

personales de los

alicatados de la

Alhambra, Granada.

Mayo 2013.

Como señala el artista y diseñador de origen marroquí Amine Asselman, "no se puede hablar del Zellige [o el alicatado] sin hablar del arte islámico [-un arte que se caracteriza por ser más conceptual que expresivo-], y, sobre todo de la geometría" (2019, p. 21). Por ello, entre los tipos de ornamentaciones del arte islámico y característicos de los alicatados andalusíes (vegetal, geométrico y caligráfico), para el proyecto Textiles Alhambrescos nos centramos en trabajar los patrones y elementos geométricos de los paños cerámicos de 
los Palacios Nazaríes de Granada, que también están presentes en otros países vecinos y limítrofes con el Mar Mediterráneo.

El motivo principal de esta selección fue porque la geometría y las matemáticas de los alicatados de la Alhambra son utilizadas como herramientas de abstracción y como forma de representación del mundo, un mundo ordenado a través de signos o motivos geométricos. En cambio, en el proyecto Textiles Alhambrescos, las formas geométricas tomadas y extraídas de los alicatados de la Alhambra dan lugar a composiciones orgánicas, representando así un mundo en desorden y en continuo movimiento como el actual (Gallego Martínez, 2013, p. 42).

Además de haber trabajado solamente con las formas geométricas de los alicatados de la alhambra, nos hemos focalizado aún más si cabe en componer nuestros diseños a partir de cuatro polígonos nazaríes provenientes del cuadrado y que se repiten abundantemente por los zócalos como son: el Pez volador (Figura 5), el Avión I (Figuras 4 y 11), el Hueso (Figura 6) y la Pajarita (Figuras 1 y 3) (Hernández y La Rubia, 2010, p. 51).

Pero no solamente las formas geométricas se repiten en nuestro proyecto personal, al igual que los alicatados de la Alhambra, también los colores aparecen y desaparecen en los diversos diseños y composiciones sin presentar un principio y un final. Así pues, la paleta cromática utilizada en nuestras nuevas creaciones está compuesta por los colores: blanco, negro, melado, azul y verde; los mismos colores que emplearon los artesanos árabes en los alicatados cerámicos de los palacios nazaríes. Para ofrecer una variedad tonal más rica, hemos utilizado diversos tonos de los colores mencionados, utilizando en cada diseño o composición tres o cuatro colores combinados, trabajando en serie (desde el punto de vista formal y cromático) y empleando técnica mixta sobre lonetas de diversos colores, principalmente.

Por tanto, el resultado final del proyecto ha sido una colección de casi una treintena de pinturas o diseños textiles contemporáneos únicos. Una serie de estampados abstractos de tipo rapportados o posicionales y rapportados multidireccionales o all-over (Rusell, 2013, pp. 68-75) de los polígonos nazaries en diversas escalas y en los que se han combinado diversos materiales y técnicas como la estampación en bloque con vinilo flexible, los marcadores Posca -rotuladores acrílicos para textil- y el hilo sobre lonetas de diversos colores. Así pues, los diseños y propuestas pictóricas también reviven los tejidos nazaríes, que se caracterizan por sus intensos colores y la utilización de motivos idénticos a los empleados en la decoración arquitectónica de la época. Por lo tanto, Textiles Alhambrescos es un proyecto híbrido de diseño, artesanía y arte contemporáneo; y con el que volvemos a exaltar nuestro legado andalusí como fuente inagotable de creación. 


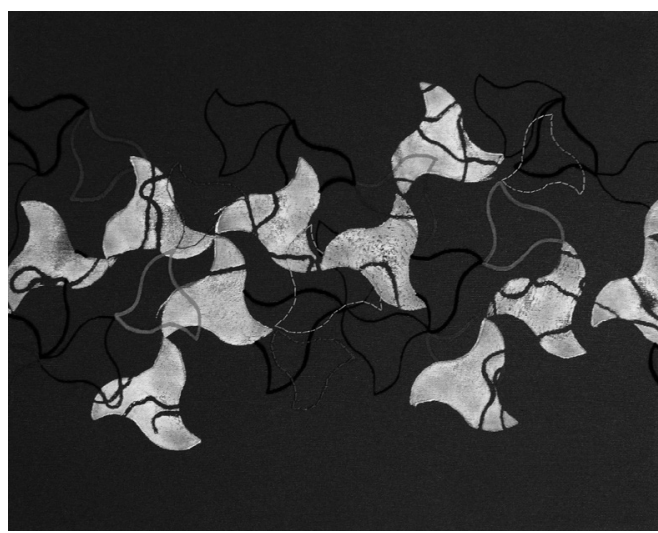

3

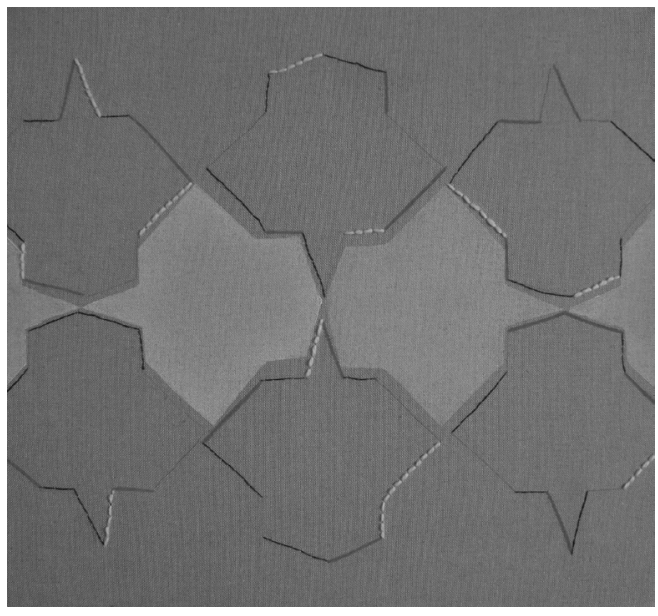

5

Figura 3. Textil Alhambresco $n^{\circ}$ XXI de $33 \times 41 \mathrm{~cm}$. Estampación en bloque, rotulador e hilos sobre loneta color azul, 2013. Colección particular del artista Jehad Al Ameri, Amán, Jordania. Figura 4. Textil Alhambresco $n^{\circ}$ XVIII de $27 \times 24 \mathrm{~cm}$. Estampación en bloque, rotulador e hilos sobre loneta color verde claro y poplín color blanco, 2013. Figura 5. Textil Alhambresco no XV de 38 x $41 \mathrm{~cm}$. Estampación en bloque, rotulador e hilos sobre loneta color gris, 2013. Figura 6. Textil Alhambresco no XIX de 100 x $100 \mathrm{~cm}$. Estampación en bloque, rotulador e hilos sobre loneta color verde oscuro, 2013.

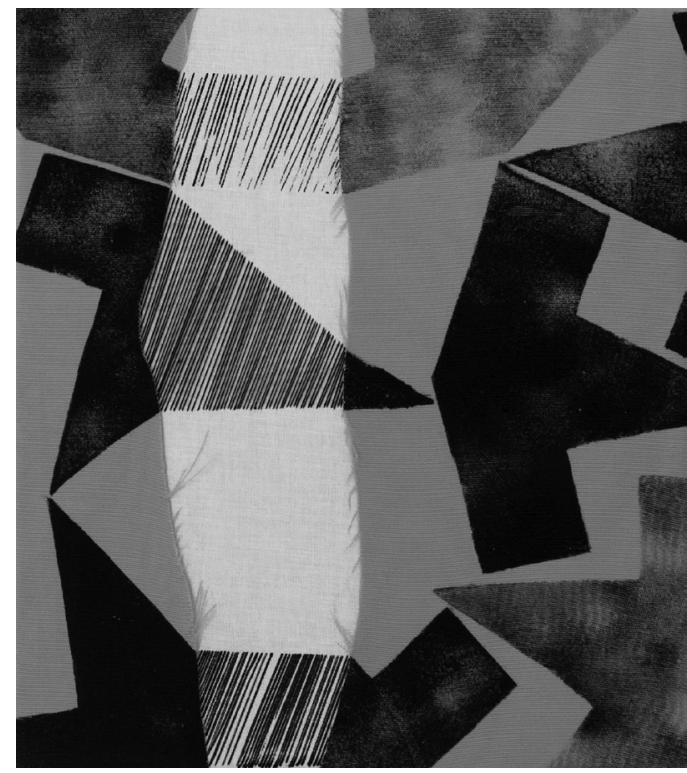

4

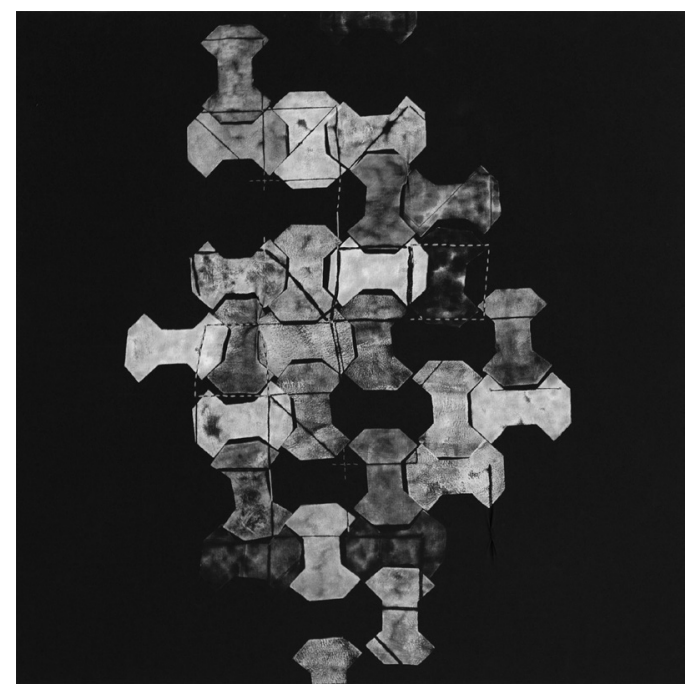

6 
En cuanto a la difusión y visibilidad del proyecto, la colección de obras al completo fue mostrada en una exposición individual (Figura 7) en la Sala de Exposiciones del Museo Histórico de Carcabuey - Córdoba (España), en el mes de julio de 2013 y enmarcada en la Programación Cultural Oficial de la localidad cordobesa.

Además, entre 2013 y 2016, las obras del proyecto han sido seleccionadas por importantes artistas y comisarios -como Belén Mazuecos o Fernando Barrionuevo, por ejemplo-para participar en una amplia gama de exposiciones colectivas, ferias de arte y otros eventos culturales nacionales e internacionales como: Muslima, International Museum of Women (Estados Unidos, 2013); Experimenta - Arte Contemporáneo, Centro de Apoyo al Desarrollo Empresarial en Almería. Sede Científica PITA de la Universidad de Almería (España, 2014); Vaginas, Centro Cultural de arte TIILLOS, Granada (España, 2014); Arte Gira MECA, Sala de Exposiciones de la Facultad de Bellas Artes de la Universidad de Granada (España, 2014); Territorio Sur'14 - Arte Contemporáneo Andaluz, Museo de Almería (España, 2014) (Figura 8); 42 Contemporary Art, diversas salas expositivas de Miami y Nueva York (Estados Unidos, 2014); Feria de arte FACBA'14, Sala de Exposiciones de la Facultad de Bellas Artes de la Universidad de Granada (España, 2014); Art for Women - VII Mostra di Mostrami, Palazzo Giureconsulti de Milán (Italia, 2014); Por amor a lo pequeño, La Casa del Carril, Carchelejo - Jaén (España, 2015); Territorio Sur'15 - Arte Contemporáneo Andaluz, Sala de la Provincia de la Diputación de Huelva (España, 2015); Arte Aparte 8, Casa de la Cultura, La Carolina - Jaén (España, 2015); y en la muestra Arts Against Terrorism and Extremism, Facultad de Arte y Diseño de la Universidad de Jordania en Amán (Jordania, 2016).

Por consiguiente, nos gustaría también subrayar la repercusión de las obras y del proyecto en su globalidad en diversos medios de comunicación como: el artículo Entre la pintura y el diseño textil. María Dolores Gallego, una peroxileña creativa con mucho futuro de la periodista Pepi Galera y publicado en el Periódico Diario Jaén, el miércoles día 11 de marzo de 2015, a página completa y a color. Por otra parte, la obra titulada Textil Alhambresco $n^{\circ}$ $V$ del proyecto que nos incumbe ilustra el libro titulado El sistema del arte emergente en Andalucía. Cartografía discontinua de agentes y contextos de intermediación, editado por Belén Mazuecos y Marilena Vecco, y publicado por LAB - Laboratorio de las Artes de Sevilla (España) en 2017 (p. 8); y, además, el proyecto Textiles Alhambrescos en su conjunto y el cuadro Textil Alhambresco no XXI (Figura 3) específicamente están recogidos en una investigación pionera de tesis doctoral sobre El Zellige (Alicatado) como soporte identitario en el arte y el diseño contemporáneo en Marruecos y España del artista de origen marroquí Amine Asselman y que fue defendida en 2019 en la Facultad de Bellas Artes de la Universidad de Vigo (pp. 131-132).

También, la investigación y creación artística de la autora en torno a este proyecto visual, se expandió en la línea del diseño de moda, planteando y llevando a cabo diversos diseños de vestimentas -como camisetas y vestidos (Figura 9)- inspirados en los nuevos diseños textiles o pictóricos que estaba generando y siguiendo la misma metodología de trabajo que en los formatos pictóricos. 


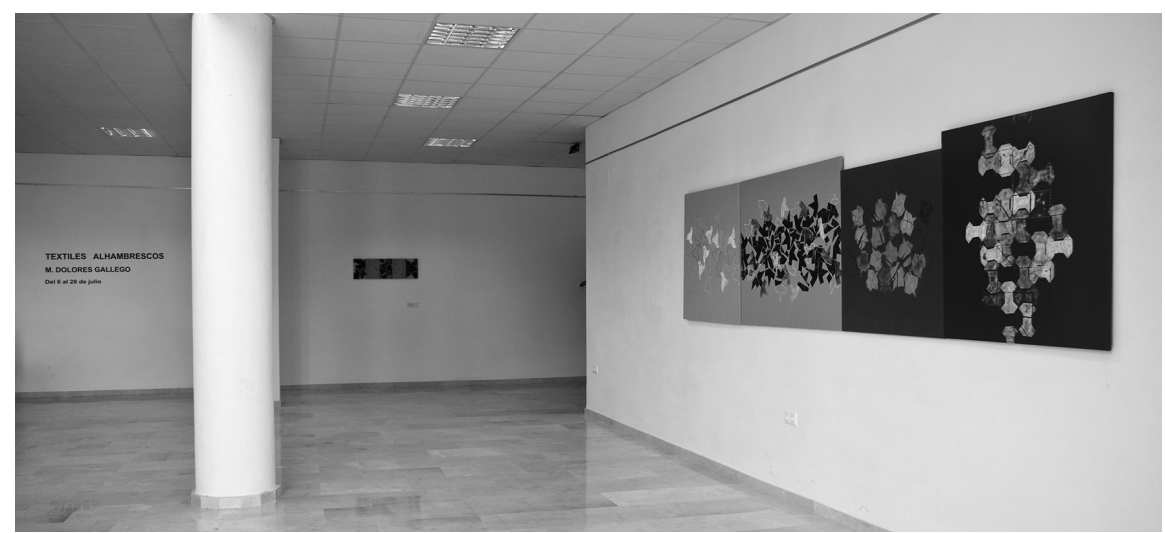

7

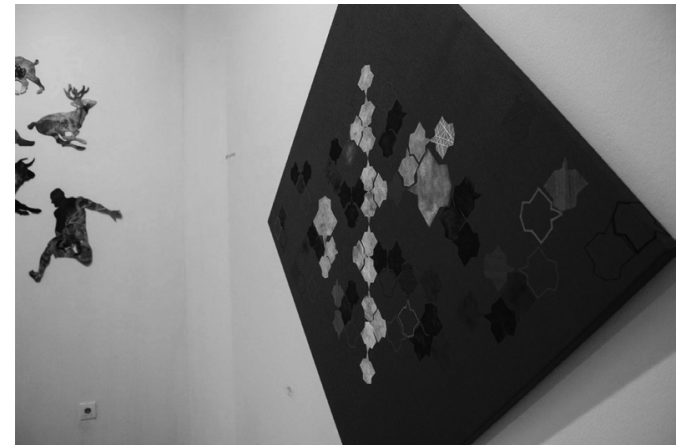

8

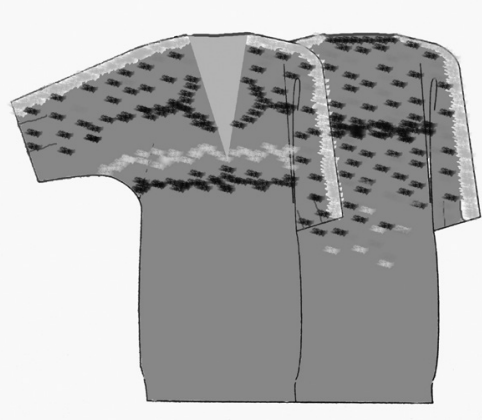

Figura 7. Vista general de parte de la exposición Textiles Alhambrescos, Carcabuey - Córdoba, Julio 2013. Figura 8. Textil Alhambresco $n^{\circ}$ XX, de 140 x $140 \mathrm{~cm}$, en la exposición Territorio Sur'14 - Arte Contemporáneo Andaluz en el Museo de Almería. Octubre - noviembre 2014. Figura 9. Diseño digital de autoría propia de Vestido Alhambresco, 2013.

Por tanto, como autora del proyecto Textiles Alhambrescos y desde el punto de vista de una docente universitaria, consideramos que este proyecto puede ser llevado a las aulas de diversos niveles educativos con éxito para, por un lado, poner en práctica el proceso de elaboración y creación de una artista contemporánea con el alumnado, trabajando con diversas técnicas y materiales artísticos y, por otro lado, para conocer parte del patrimonio cultural y artístico de Al-Ándalus en y desde cualquier parte del mundo. Así, de este modo, ponemos nuestro foco de atención en la educación a través de metodologías activas, creativas y con foco en el diseño y lo procesual. 


\section{Propuesta didáctica y creativa: la aplicación de Textiles Alhambrescos en el ámbito educativo}

Para comenzar el siguiente apartado, primeramente, es conveniente destacar que las diversas obras que componen el proyecto Textiles Alhambrescos están disponibles para su visualización a color, estudio y análisis en el siguiente enlace de la página web de la creadora: https://mariadoloresgallego.com/projects/textiles_alhambrescos/.

Aprovechando y partiendo de este recurso visual y didáctico, al que los docentes pueden acceder desde cualquier parte del mundo con tan solo disponer de conexión a internet, se puede plantear la siguiente propuesta didáctica y creativa en torno al conocimiento y la interpretación personal del arte geométrico tan característico de los alicatados cerámicos de Al-Ándalus y del Patrimonio Cultural y Artístico de este periodo de nuestra historia que hemos explicado en los apartados anteriores.

Antes de comenzar la propuesta práctica con el alumnado, se recomienda a los docentes que ofrezcan y compartan contenido teórico sobre una serie de cuestiones importantes como: ¿Qué fue el periodo de Al-Ándalus en la Península Ibérica y cuándo aconteció? A posteriori, se recomienda mostrar tanto imágenes del Complejo Monumental de la Alhambra y el Generalife de Granada como exhibir uno o varios artistas que han trabajado sobre diversos aspectos característicos o elementos decorativos de este monumento en sus obras de arte contemporáneo. En este punto y como inspiración para el alumnado, nuestra propuesta sería mostrar las obras de Textiles Alhambrescos y profundizar de esta manera en este proyecto de autoría propia. Así, siguiendo estas pautas iniciales, quedaría contextualizada y explicada la temática de la práctica a realizar por el alumnado, tanto geográfica, histórica, artística como conceptualmente.

Por consiguiente, se aconseja preparar con antelación los diversos materiales artísticos y las herramientas con los que se van a trabajar y crear en el aula. Con respecto a las herramientas, es conveniente disponer de una o varias superficies planas, lisas, rígidas y estables (unas mesas, por ejemplo); de diversos martillos; tijeras; múltiples planchas de vinilo flexible o planchas para sellos de tamaño A4 y $0,6 \mathrm{~cm}$ de grosor (también conocidas como Blue Carving Block); cúteres; reglas; folios A4; formatos de cartón A3; impresora con tinta para imprimir en blanco y negro; rodillos de espuma; plancha de ropa y agujas de coser. En cuanto a los materiales artísticos, se van a requerir camisetas de manga corta (de tejidos lisos, sin estampados); tintas de serigrafía; hilos; y marcadores Posca o rotuladores para textiles de los colores que indicaremos más adelante.

Otra de las recomendaciones que se plantea a los docentes es trabajar con una gama de colores cerrada. Es decir, como hemos explicado anteriormente y como proyectan los diseñadores de moda en cada colección, el proyecto Textiles Alhambrescos ha sido trabajado con una serie de colores seleccionados de los motivos inspiradores (de los propios colores que componen las teselas cerámicas de los alicatados originales) como han sido el blanco, el negro, el melado, el azul y el verde. Además, se recomienda trabajar el mismo color y tono, tanto en los soportes de tejido (las camisetas de manga corta o t-shirts) como en los diversos materiales artísticos utilizados de estampado textil, pictóricos y de dibujo. Así, por ejemplo, el tono azul seleccionado debería mantener su tonalidad tanto en el tejido de la camiseta, el marcador Posca, la tinta de serigrafía como en los hilos adquiridos. De este 


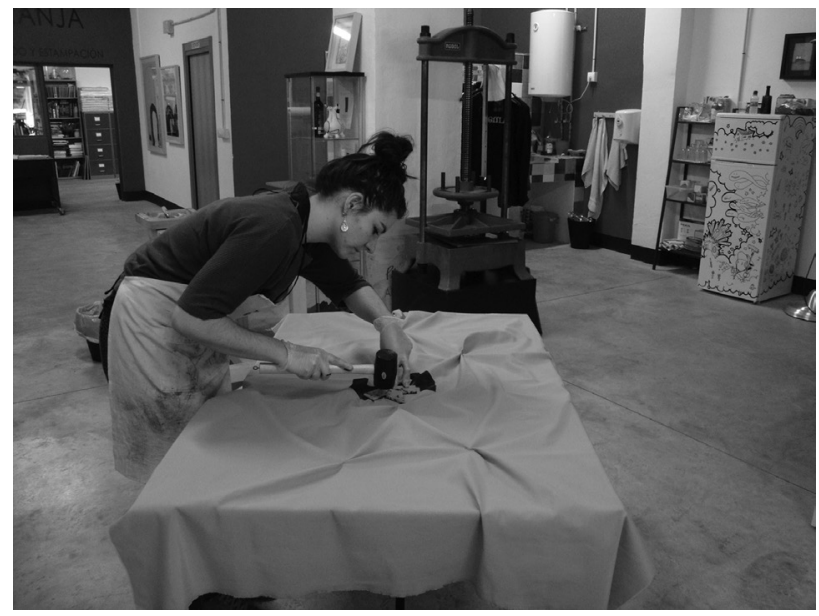

10

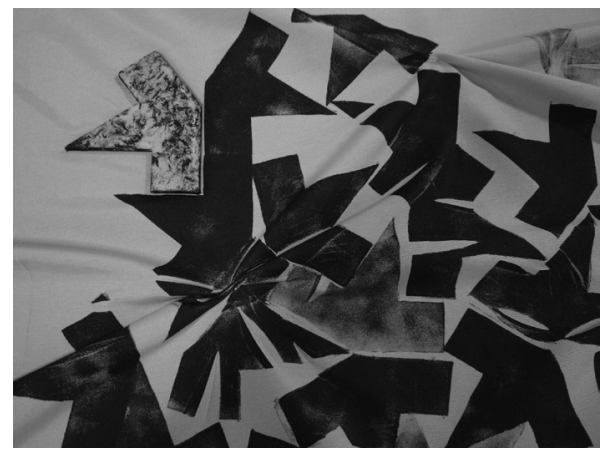

Figuras 10 y 11. María

Dolores Gallego realizando el proceso de estampación en bloque con vinilo flexible y tinta de serigrafía sobre tejido como método experimental de estampación manual. Taller de Grabado y Estampación "La Granja” de Granada.

11

modo, cada alumno/a diseñará su propia camiseta inspirada en los alicatados andalusíes a través de una composición abstracta configurada por tres o cuatro colores y formas geométricas combinadas a diversas escalas. Además, dichas formas y colores, en una camiseta a otra, como de un formato pictórico a otro, serán trabajados en serie y en cuyos diseños se empleará técnica mixta sobre las camisetas de tejido de diversos colores uniformes. De este modo, la propuesta de clase seguirá totalmente el estilo y las características del proyecto Textiles Alhambrescos, pero adaptado en este caso al diseño de una Camiseta Alhambresca. Otro de los aspectos a destacar de nuestro proyecto artístico, fue la investigación y el desarrollo técnico de un método experimental de estampación de tejidos (Figuras 10 y 11) que se puede combinar con otras técnicas tradicionales (como el bordado) e innovadoras (como son los marcadores Posca) de forma manual y artesanal, como venimos comentando. Este 
método se caracteriza por desarrollar una metodología similar a la estampación en bloque de tejidos, tan tradicional y popular en la India, pero que, en vez de tallar y emplear sellos de madera -que requieren más tiempo, precisión y práctica para su elaboración-, en nuestro caso adaptamos esta técnica milenaria a un material más reciente como es el Blue Carving Block, una plancha de vinilo flexible o plancha para sellos. Así, los sellos o bloques de madera han sido sustituidos por sellos o bloques recortados o tallados de plantas de vinilo flexible, que son más fáciles y rápidos de tallar y, en suma, la dinámica del tintado de los bloques para la estampación de tejidos prosigue siendo la misma.

Sobre las pautas o fases del proceso de creación a seguir de nuestra Camiseta Alhambresca podemos indicar que, en primer lugar, debemos de extender la camiseta de tejido seleccionada como soporte sobre una superficie lisa como es una mesa e introduciremos un formato de cartón A3 en el interior de esta para separar la capa anterior y posterior de la prenda. En este momento, se decidirá en qué punto o localización vamos a realizar nuestro diseño personal y el cartón actuará de barrera para que la tinta no traspase de una capa a otra del tejido. Antes de comenzar, también es conveniente seleccionar los materiales y colores que vamos a utilizar en serie.

A continuación, tras preparar el soporte textil, debemos crear el motivo geométrico que vamos a estampar. Para ello, podemos imprimir los polígonos nazaríes en un folio A4, a diversas escalas, y traspasar dichas formas a la plancha de vinilo flexible para, a posteriori, tallar o recortar su forma final usando un cúter. Cuando tengamos preparado la tesela geométrica seleccionada en el bloque de vinilo flexible, prepararemos la tinta de serigrafía y aplicaremos la materia pictórica sobre uno de los lados del bloque geométrico con ayuda del rodillo de espuma.

De este modo, el siguiente paso a realizar es la primera estampación sobre el punto de la camiseta que hayamos establecido para intervenir. En este momento, debemos tener precisión y cuidado para situar el bloque de estampación con la tinta de serigrafía sobre la superficie de la camiseta. Para realizar la estampación correctamente, podemos aplicar presión con nuestras propias manos o ayudarnos con el martillo.

Para continuar con el diseño alhambresco, podemos repetir este paso tantas veces deseemos, podemos seguir un patrón geométrico más rígido o estructurado o podemos desarrollar una propuesta de abstracción libre y personal como los diversos diseños que componen el proyecto Textiles Alhambrescos. También, para ir configurando la composición final, podemos plantear la composición en una o varias capas o superposiciones, utilizando simplemente la estampación en bloque o, después de secar al aire libre, también podemos emplear técnica mixta, incorporando dibujos a hilo (haciendo uso de la aguja de coser) o con rotuladores textiles (como los marcadores Posca). Esta parte de creación y expresión personal quedaría a decisión y libertad de cada alumno/a.

Cuando cada individuo decida que la composición alhambresca está finalizada, debemos esperar a que la tinta de serigrafía y/o los marcadores Posca estén bien secos y no mantengan humedad para, primero, retirar el formato de cartón A3 del interior de la prenda y, en segundo lugar, proceder al planchado a alta temperatura y sin vapor de la camiseta, justo por la parte posterior del tejido, concretamente por la zona por la que se ha procedido a realizar la estampación en bloque o el dibujo con marcadores Posca. De este modo, aplicando calor con una plancha, fijaremos las diversas tintas al tejido para que las camisetas 
puedan ser usadas en repetidas ocasiones y se puedan lavar a máquina en frío o a unos $30^{\circ}$ máximo. Así, la conservación de los colores y formas en el tejido será más adecuada y duradera.

Con esta propuesta didáctica y creativa, que sigue una metodología con foco en lo procesual, además de diseñar una prenda de vestir realizamos una práctica artística y educativa en torno a la composición con puntos, líneas, formas geométricas, superposición de capas, movimientos rotatorios, simetría, etc. Es decir, fomentaremos la creatividad y personalidad de cada alumno/a con un trabajo práctico en el aula en el que se aprende haciendo o learning by doing, como también se denomina a esta dinámica o metodología de aprendizaje-enseñanza.

\section{Conclusiones}

A modo de reflexiones finales, nos gustaría subrayar la importancia de dar a conocer a las generaciones más jóvenes el Patrimonio Artístico y Cultural que hemos heredado. En suma, desde nuestra propia experiencia vivida -como artista visual, investigadora y docente universitaria- podemos asegurar que este tipo de propuestas didácticas y creativas fomentan la formación artística y la educación patrimonial en el alumnado. En suma, los alumnos aprenden a trabajar siguiendo un proceso de investigación y creación artística real, trabajando con sus propias manos, usando diversos medios y lenguajes artísticos y empleando múltiples herramientas y materiales combinadamente. En definitiva, de esta manera, por una parte, se adquiere la capacidad de conocer, comprender, apreciar y valorar críticamente las manifestaciones culturales de diversos contextos geográficos y periodos históricos, pero también el alumnado desarrolla su propia capacidad estética y creadora, respetando la diversidad cultural y artística, a través de las prácticas artísticas contemporáneas y conociendo a artistas actuales.

Como docentes, en nuestras aulas debemos fomentar una metodología de enseñanza y aprendizaje activa, es decir, es conveniente que el alumnado aprenda haciendo. La adquisición de competencias a través del arte y el conocimiento del patrimonio resulta evidente, pero tenemos que despertar el interés de nuestro alumnado en estos ámbitos. Así, el alumnado desarrollará su creatividad creando su diseño alhambresco, propio y único, pero también comprenderá el significado, el valor y la importancia de la conservación y difusión del patrimonio artístico y cultural a nivel mundial.

Conocer de dónde venimos y lo que fuimos es fundamental para saber qué somos y a dónde nos dirigimos.

\section{Bibliografía}

Asselman, M. A. (2019). Zellige y creación contemporánea en Marruecos y España: El Zellige (Alicatado) como soporte identitario en el arte y el diseño [Tesis Doctoral]. Pontevedra: 
Universidad de Vigo. http://www.investigo.biblioteca.uvigo.es/xmlui/handle/11093/1374 $(04 / 04 / 2021)$

Cabrera, H. I. (1994). Islam y Arte Contemporáneo. Salobreña (Granada): Junta Islámica, Centro de Documentación y Publicaciones.

Gallego Martínez, M. D. (2013). Textiles Alhambrescos. Aplicación del proyecto artístico personal al diseño textil contemporáneo [Trabajo Fin de Máster]. Granada: Universidad de Granada.

Hernández, F. y La Rubia, L. (coords.) (2010). Arte y Geometría. Granada: Editorial Universidad de Granada.

Llull, J. (2005). Evolución del concepto y de la significación social del Patrimonio Cultural. Revista Arte, Individuo y sociedad, vol. 17, pp. 177-206. https://revistas.ucm.es/index.php/ ARIS/article/view/ARIS0505110177A/5813

Muñoz Rey, Y. (2021). La expresión plástica en la educación infantil. Almería: Editorial Universidad de Almería.

Patronato de la Alhambra. (s.f.a). Patrimonio Mundial. https://www.alhambra-patronato. es/descubrir/alhambra-y-generalife/conservacion-y-proteccion/urbanismo/patrimoniomundial (01/04/2021)

Patronato de la Alhambra. (s.f.b). La Alhambra en el imaginario de los viajeros románticos. https://www.alhambra-patronato.es/elemento-del-mes/la-alhambra-en-el-imaginariode-los-viajeros-romanticos $(01 / 04 / 2021)$

Rubio, C. (2020). El patrimonio arquitectónico como recurso de educación artística y de sensibilización ciudadana. Una propuesta didáctica en torno a las Murallas de Jayrán (Almería) para Educación Secundaria [Trabajo Fin de Máster]. Almería: Universidad de Almería.

Rusell, A. (2013). Diseño definitivo: rapportado y posicionamiento, en Principios básicos del diseño textil. Barcelona: Editorial Gustavo Gili, pp. 68-75.

Siegmund, J. (2011). ¿Saber versus creatividad? Sobre las modalidades de descripción del artey su relación con los contextos económicos y sociales. Viena: Instituto Europeo para Políticas Culturales Progresistas. https://transversal.at/transversal/0311/siegmund/es

Tapia Gómez, M. (2011). Un lugar para el patrimonio la conservación del patrimonio cultural en la red. Ar@cne: Revista electrónica de Recursos en Internet sobre Geografía y Ciencias Sociales, (153). http://www.ub.edu/geocrit/aracne/aracne-153.htm

\begin{abstract}
This article presents a didactic and creative teaching innovation proposal that is part of the Educational and Cultural Program called "Living and Feeling the Heritage" of the Regional Ministry of Education and Sports of the Junta de Andalucía. Based on the experience and knowledge of the author herself -as a visual artist, researcher and lecturer-, a project is offered around Arts and Heritage Education of a marked innovative character and with a focus on the Monumental Site of the Alhambra and the Generalife of Granada (Spain). Thus, through research, design and artistic creation, the proposal will be deepened in the knowledge and the interpretation of the geometric art so characteristic of Al-Andalus ceramic tiles for its subsequent application to contemporary textile
\end{abstract}


design -and even to garment design- using manual and artisan techniques such as block printing or drawing with threads. In this way, from the educational context and applying the learning by doing methodology, the students will develop their creativity creating their own and unique textile design. Furthermore, they will also understand the meaning and value of this heritage asset of Al-Andalus, promoting their own individual and collective heritage awareness, such as the conservation and dissemination of Andalusian heritage.

Keywords: arts education - heritage education - learning by doing methodology - fabric design - Al-Andalus wall tiling.

Resumo: Este artigo apresenta-se como uma proposta didática e criativa de inovação pedagógica que faz parte do Programa Educacional e Cultural "Vivendo e Sentindo o Patrimônio" do Ministério da Educação e do Esporte da Junta de Andalucía. A partir da experiência e do conhecimento da própria autora -como artista visual, pesquisadora e professora universitária - é oferecido um projeto em torno da Educação Artística e Patrimonial de caráter marcadamente inovador e com enfoque no Conjunto Monumental da Alhambra e no Generalife de Granada (Espanha). Assim, através da investigação, do design e da criação artística, o conhecimento e a interpretação da arte geométrica tão característica dos azulejos de $\mathrm{Al}$-Andalus serão aprofundados, para a sua posterior aplicação ao design têxtil contemporâneo -e mesmo ao design de vestuário- através de uma série de técnicas manuais e artesanais, como impressão em bloco ou desenho com fios. Desta forma, a partir do contexto educacional e aplicando a metodologia do learning by doing ou aprender fazendo, os alunos desenvolverão a sua criatividade criando o seu próprio design têxtil único, e também compreenderão o significado e o valor deste bem patrimonial de Al-Andalus, promovendo tanto a sua própria consciência patrimonial individual e coletiva, quanto a conservação e divulgação do património andaluz.

Palavras chave: educação artística - educação patrimonial - metodologia do learning by doing - design têxtil - azulejo andaluz.

[Las traducciones de los abstracts fueron supervisadas por el autor de cada artículo] 